Journal of Engineering and Science Research 3 (2): 27-37, 2019

e-ISSN: 2289-7127

(C) RMP Publications, 2019

DOI: $10.26666 / \mathrm{rmp}$.jesr.2019.2.5

\title{
Investigation on Influence of Infill Pattern and Layer Thickness on Mechanical Strength of PLA Material in 3D Printing Technology
}

\author{
Ei Ei Cho ${ }^{l}$, Ho Hin Hein ${ }^{1}$, Zarni Lynn ${ }^{1}$, Saw Jiemie Hla ${ }^{1}$, and Thanh Tran ${ }^{2}$, \\ ${ }^{1}$ Graduate Student, Department of Global Production Engineering and Management, Vietnamese- \\ German University, 2 Le lai, Thu Dau Mot, Binh Duong, Vietnam \\ ${ }^{2}$ Lecturer, Department of Global Production Engineering and Management, Vietnamese-German \\ University, 2 Le lai, Thu Dau Mot, Binh Duong, Vietnam
}

\begin{abstract}
This report is influencing infill density and layer thickness on mechanical strength of Poly-lactic Acid (PLA) material in three-dimensional printing machine. According to use Additive Manufacturing technology in PLA material used Fused Deposition Modeling (FDM) technique. In this project, nine samples are tested for different infill pattern (Zig zag, Triangles \& Grid) and different layer thickness $(0.2,0.1 \& 0.15) \mathrm{mm}$ by using Taguchi Method. Here we demonstrate an empirical method utilizing a statistical design of experiment technique and standardized mechanical testing which ultimately exposes trends and variable interactions specific to our selected additive manufacturing process. We collect data then converted to stress and strain values in order to construct stress vs. strain diagram and try to use a few basic formulas, mechanical properties such as modulus, yield stress, ultimate tensile stress, and percent elongation were able to be determined for each geometrical infill density and thickness layers. The results for each sample were then compared and made design of experiments (DoE) for research best design and quality. A computer simulation like NX was also done in order to reflect on the predictability of the printed specimen's performance. The aim of doing this report is how to operate 3D printing and use relevant application such as NX, Cura Software, Weka, Minitab, MATLAB and implementation of tensile strength for our samples.
\end{abstract}

Key words: Additive Manufacture Technology, Fused Deposition Modeling, three-dimensional printing, Tensile Strength, Infill density percentage, Layer thickness layers, Poly-lactic Acid, Design of Experiments.

\section{Introduction}

Our world is changing with new technologies in every second. "Complexity is free" is a phrase often used when discussing additive manufacturing (AM), which allows for almost any geometric form to be fabricated. Traditional manufacturing methods impose several limitations to the geometry of a part, especially when balancing fabrication technique and cost. This burden of free complexity can be very costly when performing design for manufacture (DFM), where the intended manufacturing method is AM. Threedimensional (3D) printing is getting important in product development sector for industry manufacturing. By using 3D printing, able to produce complex prototype products with advance functions/ parameters like variety of printer speed, temperature, infill pattern and so on.

We reviewed some related research papers for our project. In the literatures, there were several studies investigating such as Ref: [1], and it gives us to understand how to approach the main points by using methods and tools. The research paper which is Reference [2], the next one is Reference [3] and fourth paper is Reference [4], they got us know why the infill design and how infill parameters effected on mechanical strength. The last one is Reference [5] and it gave us how layer thickness is influence on property of PLA including mechanical strength of it. These studies are simple in scope, as they do not examine the interaction or non-linearity with different build parameters (e.g. layer thickness vs. infill pattern), nor do they apply statistical methods to determine treatments that will

Corresponding Author: Thanh Tran, Department of Global Production Engineering and Management, Vietnamese-German University, 2 Le lai, Thu Dau Mot, Binh Duong, Vietnam, thanh.tt@vgu.edu.vn 
efficiently explore the design space to better understand relationships between parameters and mechanical properties. Instead, these studies investigate the mechanical properties' dependence on infill shapes, infill parameters, infill design of the printed products, and by using the different layer thickness in the design process. It is possible to favor properties such as tensile strength or ductility.

This paper investigates the effect of two primary printing parameters on tensile properties of 3D printed poly-lactic acid (PLA): layer thickness and infill pattern, on several mechanical properties including strength, stiffness, and ductility. The goal of this investigation is to examine both the individual effects of the printing parameters on the mechanical properties, as well as the coupled or interactive effects. A design of experiments approach with two factors was employed to explore and examine relationships between the printing parameters and standardized mechanical testing results.

We used some methods and tools to analyze the results. Taguchi method was used to make the testing experiments of the product qualities and development of designs for studying variations by using Minitab tool. Tensile testing method was used to test the results of PLA strength depending on the different parameters. Then, in order to make regression we will use Weka software to find the solutions. Furthermore, we will get the equation from making regression. We will use ANNOVA tool to support other statistical tools meanwhile MATLAB tool will be used to make optimization. Finally, we will find the final solution of our problem.

\section{Experiments}

\subsection{Experimental Set Up}

\subsubsection{Sample Design}

It is necessary to know the properties of the material used in order to anticipate its behavior and to prevent breakage whenever making the product design. In material science and engineering field, the most commonly used for testing are tensile testing which also known as tension testing to measure the technical properties such as ultimate tensile strength, breaking strength, maximum elongation and reduction in area .From the these results, yield strength, and strainhardening characteristics can be determined.

The following recommendations of the standards sample design for the specimen is used to perform the tensile test.

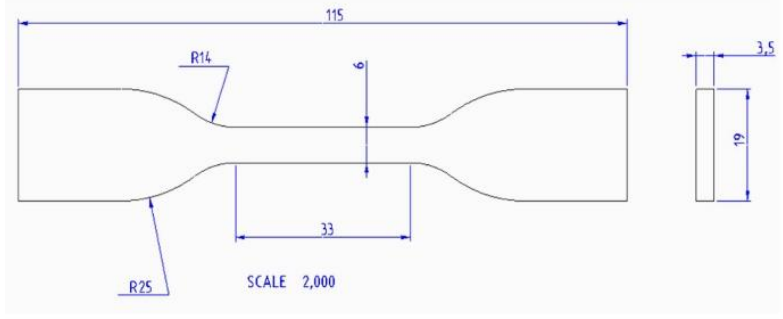

Figure (2.1) Sample diagram of specimen

Distance between grips $=65 \mathrm{~mm}$

Gage length $=25 \mathrm{~mm}$

NX design -- > STL file

These test specimens have two shoulders and a gage (section) in between. The shoulders are large so they can be readily gripped and the distance between two gripped shoulders are $65 \mathrm{~mm}$, whereas the gauge section has a smaller cross-section with the length of $25 \mathrm{~mm}$ so that the deformation and failure can occur in this area.

\subsubsection{Material Properties}

Contents of the journal in 3D printing variety of materials can be available, such as ABS and PLA plastics, glass filled polyamide, stereo lithography materials (epoxy resins), polyamide (nylon), silver, titanium, steel, wax, photopolymers and polycarbonate. Among them Acrylonitrile Butadiene Styrene (ABS) and Polylactic acid (PLA) are most popular printing materials.

Both of ABS and PLA are thermoplastic and they become soft and moldable state when heated and then return to the solid state when it is cooled by room temperature. Both of them are best material for FMD process by building up the layer to create the good finish final parts. The table below shows the comparison between main material properties of ABS and PLA. 
Table (2.1) ABS and PLA material properties comparison

\begin{tabular}{|c|c|c|}
\hline Properties* & $\mathrm{ABS}$ & PLA \\
\hline Tensile Strength** & $27 \mathrm{MPa}$ & $37 \mathrm{MPa}$ \\
\hline Elongation & $3.5-50 \%$ & $6 \%$ \\
\hline Flexural Modulus & $2.1-7.6 \mathrm{GPa}$ & $4 \mathrm{GPa}$ \\
\hline Density & $1.0-1.4 \mathrm{~g} / \mathrm{cm}^{3}$ & $1.3 \mathrm{~g} / \mathrm{cm}^{3}$ \\
\hline Melting Point & N/A (amorphous) & $173^{\circ} \mathrm{C}$ \\
\hline Biodegradable & No & $\begin{array}{l}\text { Yes, under the correct } \\
\text { conditions }\end{array}$ \\
\hline $\begin{array}{l}\text { Glass Transition } \\
\text { Temperature }\end{array}$ & $105^{\circ} \mathrm{C}$ & $60^{\circ} \mathrm{C}$ \\
\hline Common Products & $\begin{array}{l}\text { LEGO, electronic } \\
\text { housings }\end{array}$ & Cups, plastic bags, cutler \\
\hline
\end{tabular}

\section{Part accuracy}

Generally, the tolerances and accuracy of FDM printed components are mostly dependent upon printer calibration and model designs. However, ABS and PLA can be used to produce dimensionally accurate parts with good finished surface.

Due to its lower printing temperature, PLA, when properly cooled, is less likely to deviate (making it easier to print with) and can print sharper corners and features compared to ABS.

\section{Strength}

With similar tensile strengths, ABS and PLA are both adequate for many prototyping applications. ABSs have a higher flexural strength and better elongation before breaking, whereas PLA remains popular for rapid prototyping when form is more tensile strength than ABS.

\section{Surface finish and post processing}

For both ABS and PLA, the print layers will be visible after printing through FDM process. ABS typically print in a matte surface while PLA is semitransparent, often resulting in a polish finish surface.

\section{Temperature}

PLA is easy to use in $3 \mathrm{D}$ printer has a melting temperature of around 190-210 degree Celsius so it can easily be melted also it cools faster.

\section{Biodegradability}

PLA is stable in general room temperature conditions and will biodegrade within 50 days in

industrial composters and 48 months in water. ABS is not biodegradable; however, it is recyclable. PLA is regularly used to produce food related items.

Overall, PLA is great for experimentation and is just another reason for its material properties to use in our FDM process.

\subsubsection{Process to Experiments (phase one)}

The graph below shows the process flow of the experiment.

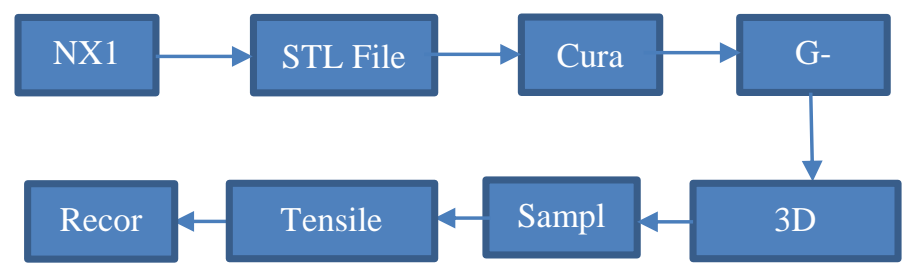

\section{Diagram (2.1) Flow Chart of Experiment}

1. At the very beginning of the phase one, the standard sample design of the specimen is drawn in NX CAD modeling software.

2. This drawing is exported as STL file.

3. In Cura software we run this STL file and define the parameters such as temperature, layer thickness, pattern and so on.

4. Then change this into G-code to produce the real sample in 3D printer.

5. Produce the sample specimen in 3D printer

6. Placed them into tensile test machine and do experiments and record it.

\subsubsection{Process to Experiments (phase two)}

In this phase two the results data from the tensile testing have to analyze, optimize and simulate by specified tools.

Analyze

Optimize

Simulatio
The experimental results data is analyzed by Weka, Taguchi and excel to get the Influence factors and regression function.

Optimization with MATLAB and excel to get the optimized number.

Numerical simulation and actual simulation which are to validate the result from optimized values. 


\subsubsection{Preparation}

In preparation process for this project, applied two software which are NX 10 for design products and Cura for parameter selection. Followed to our design then drew in NX 10 then convert .stl file to input data into Cura software. The following figures are the three different patterns when we run simulation in Cura.

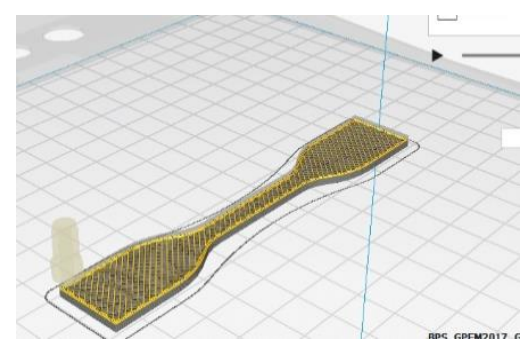

Figure (2.2) ZigZag Pattern in Simulation

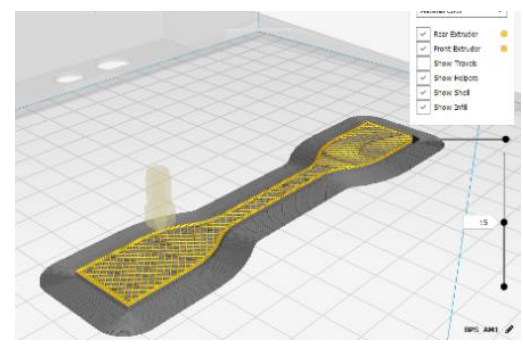

Figure (2.3) Grid Pattern in Simulation

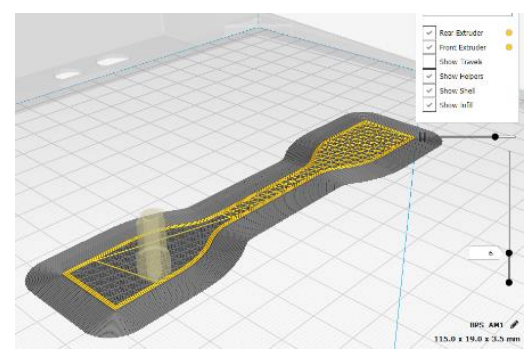

Figure (2.4) Triangle Pattern in Simulation

\subsubsection{Printing}

After designed of our samples in NX 10 \& Cura, need to print out in Fused Deposition Modelling (FDM) 3D printing machine. In GPEM lab had five Builder 3D printing machines. In these machines can print two type of plastic material which are ABS and PLA. But in our product used PLA to build samples as mentioned before. The detail information for these printing machines are as per below.

- Print Technology : FDM

- Build volume : 220 (L) x 210 (B) x 164 (H) $\mathrm{mm}$
- Printer Dimension : 385 (L) x 370(B) x 400(H) $\mathrm{mm}$

- Weight : $15 \mathrm{~kg}$

- Print speed $\quad: 10 \sim 80 \mathrm{~mm} / \mathrm{s}$

- Nozzle diameter : $0.4 \mathrm{~mm}$

- Operating Temperature for nozzle : 180 250'C

- Power : $12 \mathrm{~W}$

Using by these $3 \mathrm{D}$ printing machine then put some parameter for our samples. Need to fit following parameters in Cura software to make the G-code for the printing in 3D printing machine.

\begin{tabular}{|l|l|l|}
\hline Parameter & Value & Unit \\
\hline Printing speed & 50 & $\mathrm{~mm} / \mathrm{sec}$ \\
\hline Infill density & 30 & $\%$ \\
\hline Printing Temperature & 215 & $\begin{array}{l}\text { Degree } \\
\text { Celsius }\end{array}$ \\
\hline Shell wall thickness & 0.8 & $\mathrm{~mm}$ \\
\hline Printing location & Center & - \\
\hline Orientation Angle & 0 & Degree \\
\hline
\end{tabular}

Table (2.2) Fixing parameters

According to our project requirements, kept two factors that are "Infill pattern" and "Layer thickness" then other parameters are changed with three levels. For infill pattern, choice three types of pattern which are Zigzag, Grid and Triangle. For more details can see in the following table.

\begin{tabular}{|l|l|l|l|l|l|}
\hline $\begin{array}{l}\text { Sample } \\
\text { number }\end{array}$ & $\begin{array}{l}\text { Infill } \\
\text { Pattern }\end{array}$ & $\begin{array}{l}\text { Layer } \\
\text { Thickness } \\
(\mathbf{m m})\end{array}$ & $\begin{array}{l}\text { Time } \\
(\mathbf{m i n}\end{array}$ & $\begin{array}{l}\text { Length } \\
(\mathbf{m m})\end{array}$ & $\begin{array}{l}\text { Weight } \\
(\mathbf{g})\end{array}$ \\
\hline 1 & Zigzag & 0.20 & 26 & 1.57 & 5 \\
\hline 2 & Zigzag & 0.15 & 29 & 1.43 & 4 \\
\hline 3 & Zigzag & 0.10 & 36 & 1.31 & 4 \\
\hline 4 & Grid & 0.20 & 26 & 1.54 & 5 \\
\hline 5 & Grid & 0.15 & 29 & 1.40 & 4 \\
\hline 6 & Grid & 0.10 & 36 & 1.28 & 4 \\
\hline 7 & Triangle & 0.20 & 26 & 1.54 & 5 \\
\hline 8 & Triangle & 0.15 & 29 & 1.39 & 4 \\
\hline 9 & Triangle & 0.10 & 37 & 1.27 & 4 \\
\hline
\end{tabular}

Table(2.3) Experiments of Printing

Based on these data made three batches for experiments. Each batch had nine samples so total is twenty seven samples for print. Following figures are the real printing samples with three different pattern. 


\section{Pattern\#1}

(ZigZag)

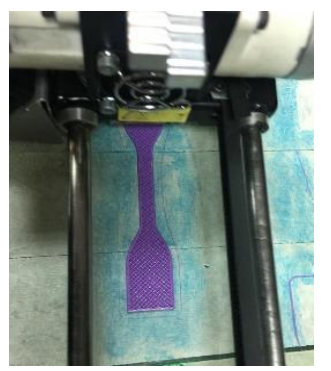

Figure (2.5) ZigZag Pattern in Reality Printing

\section{Pattern\#2}

(Grid)

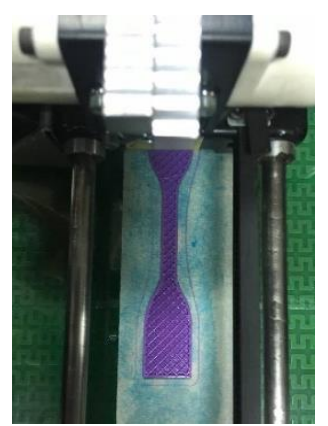

Figure (2.6) Grid Pattern in Real Printing

\section{Pattern\#3 \\ (Triangle)}

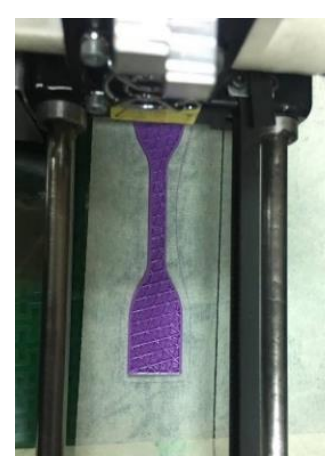

Figure (2.7) Triangle Pattern in Real Printing

During printing process faced little challenge for our group. For example, unfamilier with printing machine, lack of preparation, gcode files unreadable, machine's minor problem and so on. Following photo is record for failure samples durin our printin process.

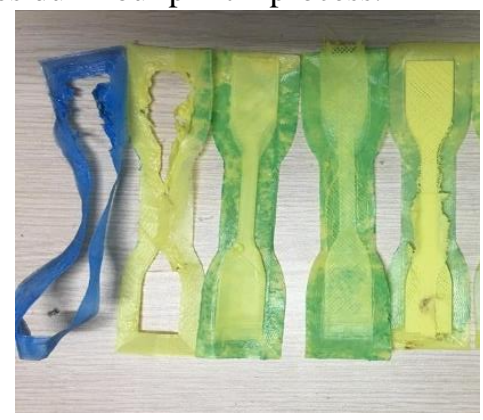

Figure (2.8) Some Failure Samples
After finished printing all samples, made marking and prepare with calibration tools to check dimensions and thickness then move to tensile testing process.

\subsubsection{Testing}

In GPEM lab can test SHIMADZU tensile test machine which is made in Japan with TRAPEZIUM X software. These machines can determine tensile, compression, flexural (bending), peel, shear, tear and seal strength for various material using relevant ASTM and ISO methods. And can select manual adjustment for position of tools. In our case want to test tensile with different pattern and layer thickness. Before testing need to set up basic data in the software as per below information.

\begin{tabular}{|l|l|}
\hline \multicolumn{2}{|l|}{ Machine Name : Shimadzu } \\
\hline Apply Software :Trapezium X \\
\hline Test Mode & Tension \\
\hline Test Speed & $1.5 \mathrm{~mm} / \mathrm{min}$ \\
\hline Max: Force & $1000 \mathrm{~N}$ \\
\hline Min: Force & $5 \mathrm{~N}$ \\
\hline Unit & SI \\
\hline Specimen & Plastic, Plate \\
\hline Testing direction & Up \\
\hline
\end{tabular}

Table(2.4) Information of Tension Machine

Our testing process divided by three batches each batch had nine samples. We did dimension measurements like width, thickness and gauge height of samples with calibration tool before testing. When finished input data, have to calibrate between machine and software in zero force and positions. Before starting the testing, we need to check samples depositions are fix or not and also need to tight with tools.

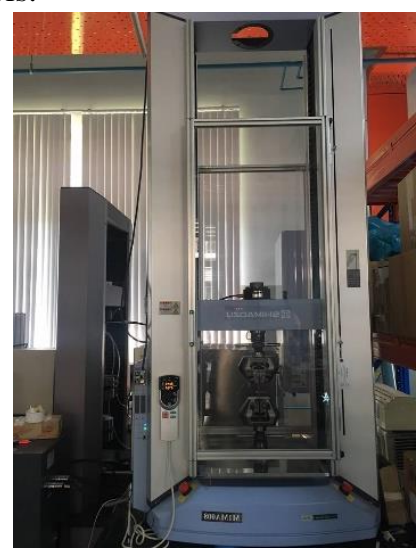

Figure (2.9) Tension Testing Machine in GPEM Lab 
After testing with machine, export data with PDF and excel file into computer then can compare results for further experimental processes.

\subsection{Design Experiments}

\subsubsection{Taguchi Method}

Taguchi method is a well-known technique that provides a systematic and efficient methodology for process optimization and this is a powerful tool for the design of high-quality systems. Besides, this is an engineering methodology for obtaining product and process condition, which are minimally sensitive to the various causes of variation, and which produce high-quality products with low development and manufacturing costs. Taguchi approach to design of experiments is easy to adopt and apply for users with limited knowledge of statistics, hence gained wide popularity in the engineering and scientific community. The objective of using Taguchi method in this paper is to investigate the mechanical strength of Poly-lactic Acid (PLA) materials which is used in $3 \mathrm{D}$ printing by using two factors which are infill pattern parameters and layer thickness parameters.

\subsubsection{Matrix Design}

The following control parameters which are given in Table 2.2 were selected for the investigation since they have influence on the mechanical strength of PLA. Then we had chosen two factors and three levels for this research. Signal to noise ratio and orthogonal array are two major tools used in robust design. The $\mathrm{S} / \mathrm{N}$ ratio characteristics can be divided into three categories when the characteristic is continuous (a) Nominal is the best (b) Smaller is better (c) Larger is better characteristics. For the resistance of maximum applied force, the solution is "Larger is better" and $\mathrm{S} / \mathrm{N}$ ratio is determined according to the following equation:

$$
\mathrm{S} / \mathrm{NS}=-10 \log \left(1 / \mathrm{n} \Sigma 1 / \mathrm{y}^{\wedge} 2\right)
$$

Where, $\mathrm{S} / \mathrm{NS}=$ signal to noise ratio, $\mathrm{n}=$ Number of observations,

$\mathrm{y}=$ Observed data

The influence of each control factor can be more clearly presented with response graphs. Optimal conditions of control factors can be easily determined from $\mathrm{S} / \mathrm{N}$ response graphs. Parameters design is the key step in Taguchi method to achieve reliable results without increasing the experimental costs.

\begin{tabular}{|c|c|c|c|c|}
\hline Matrix Design & \multicolumn{1}{l|}{} & \\
\hline Factors & Description & Level 1 & Level 2 & Level 3 \\
\hline A & Infill Pattern & Zig Zag & Grid & Triangle \\
\hline B & Layer Thickness & 0.2 & 0.15 & 0.1 \\
\hline
\end{tabular}

Table 2.5 Matrix Design for Parameters

\subsubsection{Experiments and Data Collection}

\section{Orthogonal array and Data collection before Printing}

Orthogonal array of L9 was selected based on the number of factor and level in Table [2.3]. Taguchi technique is used to identify the key factors that make the greatest contributions to the variation in response parameters of interest. Taguchi recommends orthogonal array (OA) for laying out of the experiments which is significant part of this method. Instead of varying one factor at a time, all factors are varied simultaneously as per the design array and the response values are observed. It can evaluate several factors in a minimum number of tests. Then, we collected the data of each item by batches before testing as per below Table [2.4]. In this research, we tested three batches to get the best result.
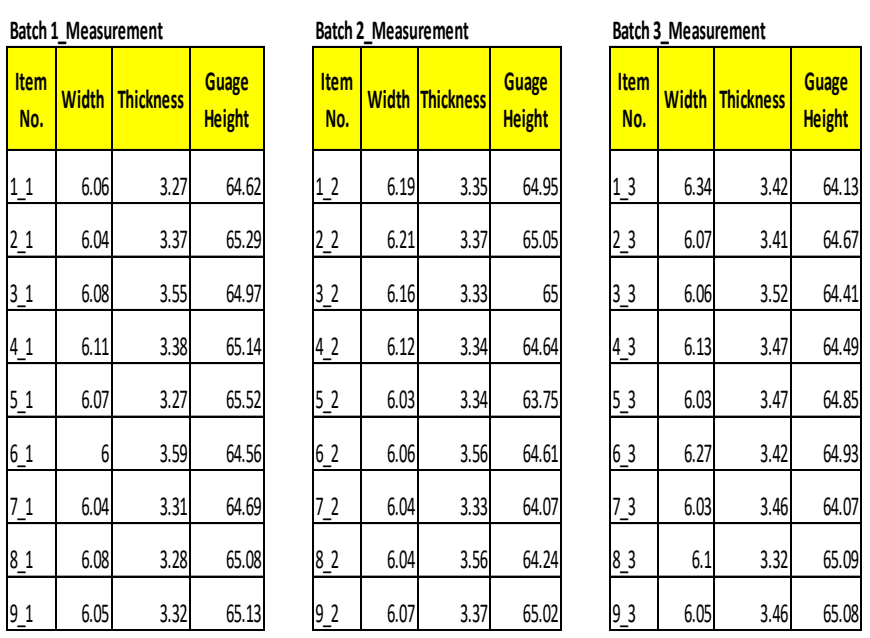

Table (2.6) Data collections of each batch before testing 


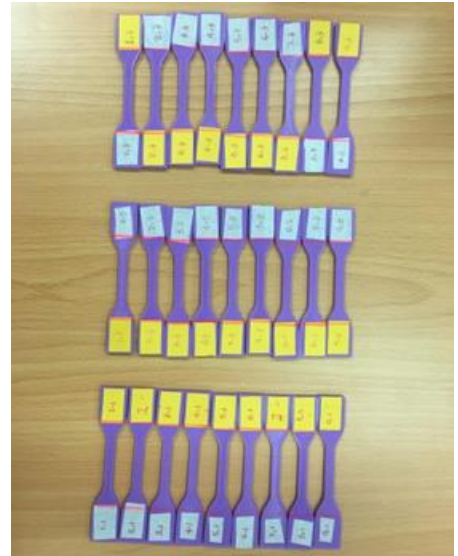

Figure 2.10 Printed items for three batches

\section{Orthogonal array and Data Collection After Printing}

As we mentioned above paragraph, we had L9 orthogonal array and we tested all three batches by collecting data batch by batch after testing in tensile machine as per below Table 2.3. Moreover, we did check the situations of cutoff point in specimens. We had seen all cutoff points of specimens are almost same places at the bottle neck of specimens in Figure [2.8].
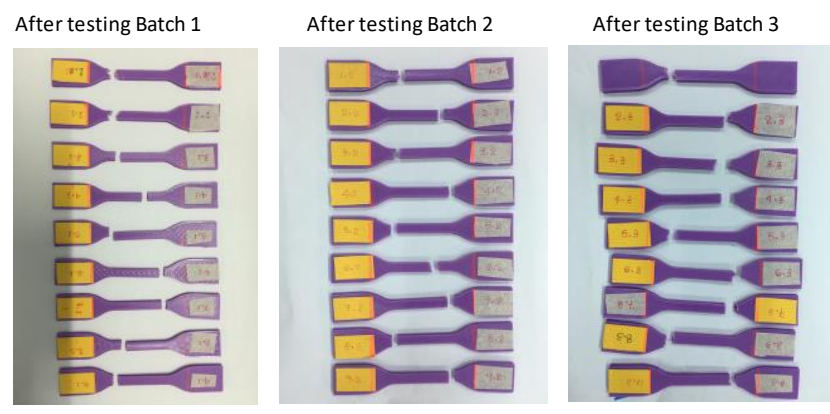

Figure [2.11] Specimens After testing

L9 orthogonal array_Test 1
\begin{tabular}{|c|c|c|c|}
\hline A & B & $\begin{array}{c}\text { Item } \\
\text { No. }\end{array}$ & $\begin{array}{c}\text { Tensile } \\
\text { strength }\end{array}$ \\
\hline 1 & 1 & $1 \_1$ & 565.2745 \\
\hline 1 & 2 & $2 \_1$ & 502.0698 \\
\hline 1 & 3 & 3_1 & 415.5556 \\
\hline 2 & 1 & $4 \_1$ & 624.8553 \\
\hline 2 & 2 & $5 \_1$ & 540.0737 \\
\hline 2 & 3 & $6 \_1$ & 482.6864 \\
\hline 3 & 1 & $7 \_1$ & 668.7164 \\
\hline 3 & 2 & $8 \_1$ & 568.4376 \\
\hline 3 & 3 & $9 \_1$ & 484.4507 \\
\hline
\end{tabular}

L9 orthogonal array_Test 2
\begin{tabular}{|c|c|c|c|}
\hline A & B & $\begin{array}{c}\text { Item } \\
\text { No. }\end{array}$ & $\begin{array}{c}\text { Tensile } \\
\text { strength }\end{array}$ \\
\hline 1 & 1 & $1 \_2$ & 599.8532 \\
\hline 1 & 2 & $2 \_2$ & 542.2115 \\
\hline 1 & 3 & $3 \_2$ & 458.8286 \\
\hline 2 & 1 & 4 _2 & 645.7646 \\
\hline 2 & 2 & $5 \_2$ & 576.7743 \\
\hline 2 & 3 & $6 \_2$ & 451.4535 \\
\hline 3 & 1 & $7 \_2$ & 646.9329 \\
\hline 3 & 2 & $8 \_2$ & 543.1573 \\
\hline 3 & 3 & $9 \_2$ & 440.1207 \\
\hline
\end{tabular}

L9 orthogonal array_Test 3
\begin{tabular}{|c|c|c|c|}
\hline A & B & $\begin{array}{c}\text { Item } \\
\text { No. }\end{array}$ & $\begin{array}{c}\text { Tensile } \\
\text { strength }\end{array}$ \\
\hline 1 & 1 & $1 \_3$ & 565.7991 \\
\hline 1 & 2 & $2 \_3$ & 541.9413 \\
\hline 1 & 3 & $3 \_3$ & 465.1626 \\
\hline 2 & 1 & $4 \_3$ & 566.5064 \\
\hline 2 & 2 & $5 \_3$ & 448.1316 \\
\hline 2 & 3 & $6 \_3$ & 358.7723 \\
\hline 3 & 1 & $7 \_3$ & 587.0978 \\
\hline 3 & 2 & $8 \_3$ & 464.3758 \\
\hline 3 & 3 & $9 \_3$ & 449.9912 \\
\hline
\end{tabular}

Table [2.7] Orthogonal array for three batches and their tensile test results

\subsubsection{Results}

The results of the experiments are analyzed to achieve the following objectives.

1. To establish the optimum conditions for the influence in $3 \mathrm{D}$ printing

2. To estimate the contributions of individual parameter to the responses

3. To predict the response under optimum conditions.

4. To run the confirmation test for validation.

The optimum condition is identified by studying the main effects of each of the parameters. The main effects indicate the general trend of influence of each parameter.

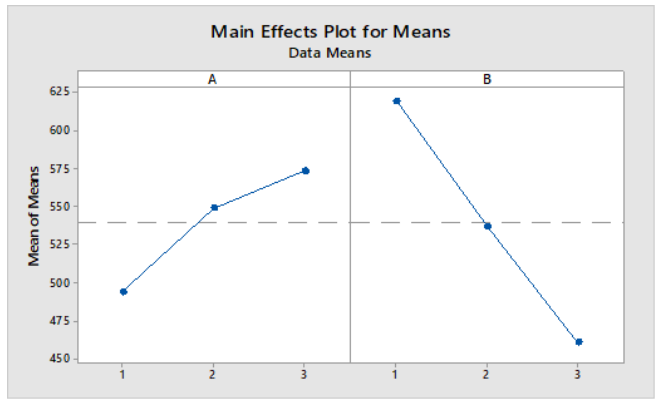

Figure (2.12) Main effects plot for Means of Batch 1

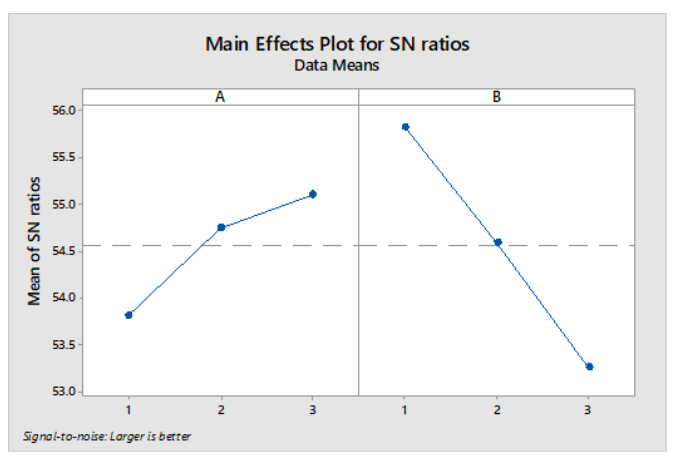

Figure (2.13) Main effects plot for SN ratios of Batch 1

Factor A for batch 1 in $\mathrm{S} / \mathrm{N}$ ratios had occurred at triangles infill pattern as the largest value while factor B is seen at $0.2 \mathrm{~mm}$ layer thickness as the biggest meanwhile we chose "lager is better" in it. Furthermore, the results of main effects for means are same as $\mathrm{S} / \mathrm{N}$ ratios. Then, we made second time experiments in order to observe the possibilities of correct results. The results are shown in following. To obtain the best $\mathrm{S} / \mathrm{N}$ ratio, the configuration and results are analyzed using the ANOVA method in [6]. Analysis results show in Fig. (2.14) and Fig. (2.15) 


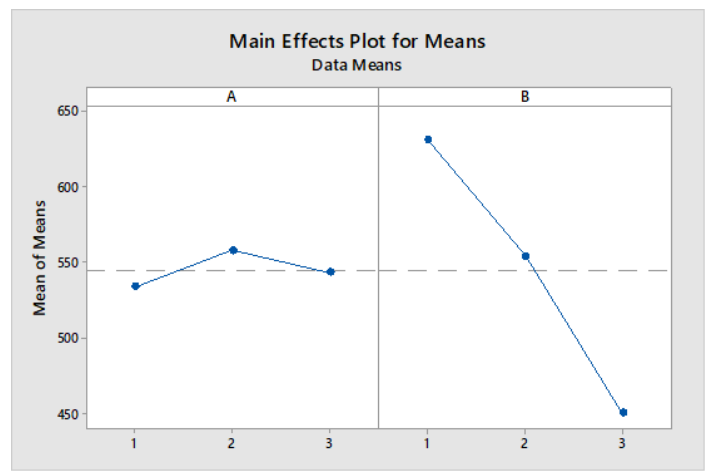

Figure (2.14) Main effects plot for Means of Batch 2

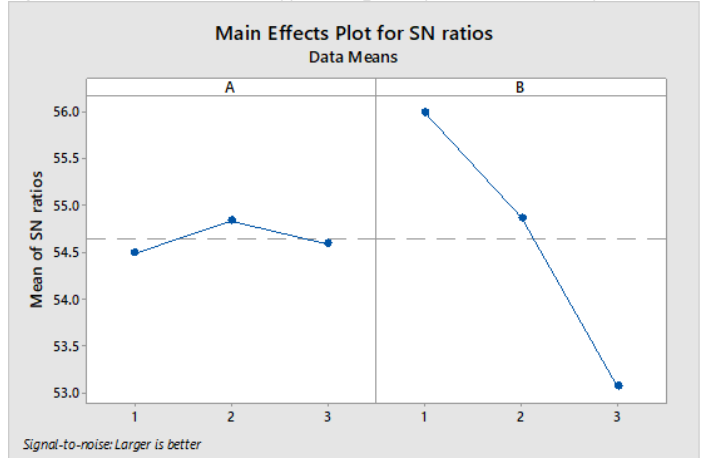

Figure (2.15) Main effects plot for SN ratios of Batch 2

$\mathrm{S} / \mathrm{N}$ ratios of factor A was moved to number two which is represented to "Grid" infill pattern and it was the largest value meanwhile factor B was at the number one same as batch one. Additionally, the results of main effects of means are shown and the output was nearly symmetrical with $\mathrm{S} / \mathrm{N}$ ratios. However, the results of two experiments are different in $\mathrm{S} / \mathrm{N}$ ratios. We then tried third batch of testing to observe the best solution. At that batch, we discovered the peak point at infill pattern number one which represented Zig zag Pattern in both of $\mathrm{S} / \mathrm{N}$ ratios and main effects while layer thickness was the same peak point at 0.2 which means at number one of factor B.

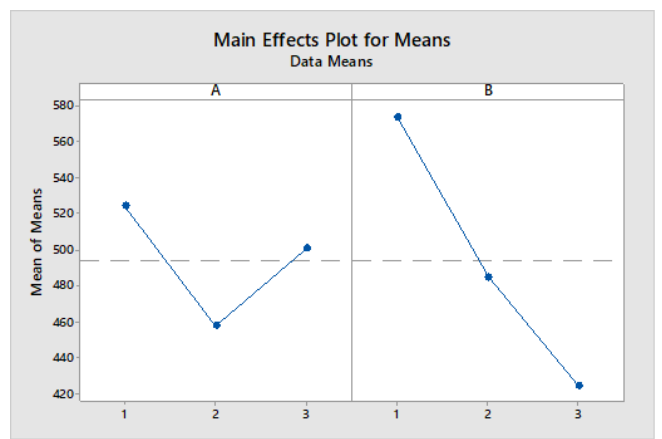

Figure (2.16) Main effects plot for Means of Batch 3

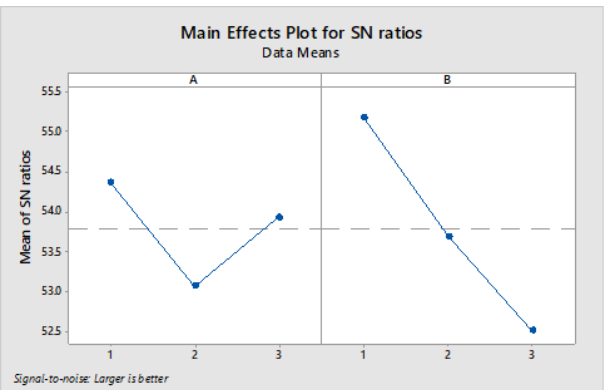

Figure (2.17) Main effects plot for SN ratios of Batch 3

In order to conclude results, we had found out the output of three batches and we observed that the results of infill pattern had changes in every batch although layer thickness had same peak point at number one which means $0.2 \mathrm{~mm}$.

\section{Optimization 3.1 Weka Software}

Weka is a machine learning software which contains tools for data preparation, classification, regression, clustering, association rules mining, and visualization. Development started from 1997 and inspired for Weka bird in New Zealand which is flightless bird with an inquisitive nature. Weka is open source software issued under the GNU General Public License. Nowadays, Weka can used in many different application areas, for educational purposes and research.

The objective for using this software in our project is to optimize our samples data, comparison of correlation coefficient between samples and to know linear regression equations for each group. In these projects, divided into three parts for regression. Each part had nine samples and parameters are layer thickness $\left(\mathrm{X}_{1}\right)$, infill pattern $\left(\mathrm{X}_{2}\right)$ and tensile result force $(\varepsilon)$. In the following data shows more detail of our regression experiments.

\subsubsection{Linear Regression Model Equation}

One problem in this case is cannot put directly patterns name into the software. So, have to convert pattern features to number. Therefore, we printed three different pattern and tested with the tensile machine then compare the results and evaluate it.

\begin{tabular}{|l|l|l|l|}
\hline Pattern & Shape & $\begin{array}{l}\text { Result } \\
\text { (Force) }\end{array}$ & Evaluate \\
\hline$\# 1$ & ZigZag & $517 \mathrm{~N}$ & 1 \\
\hline$\# 2$ & Grid & $624 \mathrm{~N}$ & 2 \\
\hline$\# 3$ & Triangle & $668 \mathrm{~N}$ & 3 \\
\hline
\end{tabular}

Table (3.1) Pattern Evaluation Results 
Based on these results, we evaluated less value into number one and biggest value into number three. After that run into the Weka software with equation.

The quadratic response model equation:

$y=\beta+\beta_{1} X_{1}+\beta_{2} X_{2}+\beta_{3} X_{1}^{2}+\beta_{4} X_{1} X_{2}+\beta_{5} X_{2}^{2}+\varepsilon$

Put $\mu_{1}=X_{1}^{2}, \mu_{2}=X_{1} X_{2}, \mu_{3}=X_{2}^{2}$

Then find in the Weka software by using these equation

$y=\beta+\beta_{1} X_{1}+\beta_{2} X_{2}+\beta_{3} \mu_{1}+\beta_{4} \mu_{2}+\beta_{5} \mu_{3}+\varepsilon$

Batch\#1

Linear Regression Model Equation:

$\mathrm{y}=1241.71 \mathrm{X}_{1}+74.36 \mathrm{X}_{2}+172.73 \mathrm{X}_{1} \mathrm{X}_{2}+(-15.12) \mathrm{X}_{2}^{2}$

$+222.89$

Summary:

Correlation coefficient $\quad 0.9302$

Mean absolute error

25.1504

Root mean squared error

27.712

Relative absolute error

$37.0219 \%$

Root relative squared error

Total Number of Instances

$33.5541 \%$

9

Batch\#2

Linear Regression Model Equation:

$\mathrm{y}=2679.56 \mathrm{X}_{1}+(-5422.18) \mathrm{X}_{1}^{2}+377.129 \mathrm{X}_{1} \mathrm{X}_{2}+(-$

13.054) $\mathrm{X}_{2}^{2}+221.8964$

Summary:

Correlation coefficient

0.9693

Mean absolute error

17.6716

Root mean squared error

19.677

Relative absolute error

$24.4352 \%$

Root relative squared error

$23.0661 \%$

Total Number of Instances

Batch\#3

Linear Regression Model Equation:

$\mathrm{y}=4955.98 \mathrm{X}_{1}^{2}+374.43$

Summary:

Correlation coefficient

Mean absolute error

0.7552

Root mean squared error

41.3668

Relative absolute error

47.5619

$58.1495 \%$

$59.516 \%$

Root relative squared error

Total Number of Instances

9

Based on above results, the maximum value of correlation coefficient is occurred in Part\#2 which is 0.9693. So, we choose these parts for our next experiments process such as Minitab to find what we expert in our project.

\subsection{Optimization by MATLAB Software}

\subsubsection{MATLAB Software}

MATLAB is a programming platform designed specifically for engineers and scientists. The heart of MATLAB is the MATLAB language, a matrix-based language allowing the most natural expression of computational mathematics. MATLAB is a highperformance language for technical computing. It integrates computation, visualization, and programming in an easy-to-use environment where problems and solutions are expressed in familiar mathematical notation. Typical uses include:

Math and computation

Algorithm development

Modeling, simulation, and prototyping

Data analysis, exploration, and visualization

Scientific and engineering graphics

Application development, including Graphical User Interface building

MATLAB can be used for several mathematical and engineering calculations and simulations. In this study, we used MATLAB optimization tool to optimize the regression equation which was derived from Weka and MS excel software in order to find the most optimal solution which give the highest mechanical properties of the product.

\subsubsection{Optimization}

After comparing the correlation coefficient of three tests, test batch 2 was chosen because of its highest correlation coefficient value. Therefore, the regression equation of batch 2 was optimized by genetic algorithm in [7] to find the optimal values. MATLAB optimization tool are used with the lower boundaries 0.1 and 1 and upper boundaries 0.2 and 3 regarding to the minimum and maximum levels of experiments. The MATLAB software only minimizes the equation and hence the regression equation was changed from $f(x)$ to $-f(x)$ in order to maximize the equation. The linear regression equation from Weka was optimized by MATLAB as below: 


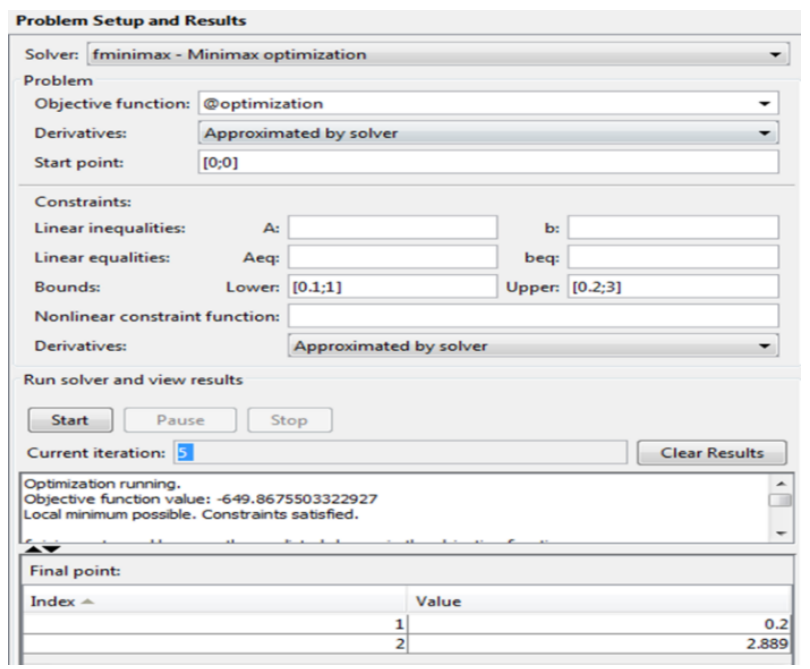

Figure (3.1) Optimization by MATLAB

According to the optimization results as above, the optimized solution for this study is as follow:

Layer Thickness $-0.2 \mathrm{~mm}$

Infill Pattern - Triangle

Maximum applied force $-649.87 \mathrm{~N}$

The maximum applied force is bigger than the forces from the experiments and hence the optimization is acceptable.

\subsubsection{Comparison with Excel Regression and Optimization}

In order to check the reliability of the optimization, the data was also analyzed by MS Excel to derive regression function and optimize value. To derive the regression function, the data analysis tool of Excel was used. The regression function and coefficients derived from Excel is as follow:

\begin{tabular}{|c|c|c|c|c|c|c|c|}
\hline \multicolumn{8}{|l|}{ SUMMARY OUTPUT } \\
\hline \multicolumn{8}{|c|}{$\begin{array}{l}\text { Regression Statistics } \\
\end{array}$} \\
\hline Multiple R & 0.996025885 & & & & & & \\
\hline R Square & 0.992067563 & & & & & & \\
\hline Adjusted R Square & 0.978846835 & & & & & & \\
\hline Standard Error & 11.69758394 & & & & & & \\
\hline Observations & 9 & & & & & & \\
\hline \multicolumn{8}{|l|}{ ANOVA } \\
\hline & $d f$ & SS & MS & $F$ & Significance $F$ & & \\
\hline Regression & 5 & 51339.09564 & 10267.82 & 75.0388 & 0.00238167 & & \\
\hline Residual & 3 & 410.5004098 & 136.8335 & & & & \\
\hline \multirow[t]{2}{*}{ Total } & 8 & 51749.59605 & & & & & \\
\hline & Coefficients & Standard Error & $t$ Stat & $P$-value & Lower 95\% & \multicolumn{2}{|c|}{ Upper $95 \%$ ower 95} \\
\hline Intercept & 184.9499 & 83.99122312 & 2.202015 & 0.114955 & -82.34765769 & 9452.24746 & -82.34 \\
\hline $\mathrm{X}$ Variable 1 & 2775.937667 & 1024.234642 & 2.710256 & 0.073149 & -483.634087 & 76035.5094 & -483.6 \\
\hline$X$ Variable 2 & 33.46596667 & 37.75378981 & 0.886427 & 0.440677 & -86.68344223 & 3 153.61538 & -86.68 \\
\hline $\mathrm{X}$ Variable 3 & -5422.18 & 3308.57637 & -1.63883 & 0.199779 & -15951.54664 & 4 5107.1866 & -15951 \\
\hline$X$ Variable 4 & 328.938 & 116.9758394 & 2.812017 & 0.067181 & -43.33132777 & 701.20733 & -43.33 \\
\hline$X$ Variable 5 & -19.4801 & 8.271440925 & -2.3551 & 0.099842 & -45.80351661 & 16.8433166 & -45.80 \\
\hline Layer Thickness(X1) & Infill Pattern(X2) & $x 1^{\wedge} \mathbf{2}$ & $\mathrm{X} 1 \times \mathrm{X} 2$ & $x 2^{\wedge 2}$ & Force (N) & & \\
\hline \begin{tabular}{|c|}
0.2 \\
\end{tabular} & \begin{tabular}{|l|}
2.547901675 \\
\end{tabular} & 0.04 & 0.50958 & 6.491803 & 649.6775978 & & \\
\hline
\end{tabular}

Table (3.1) Regression and Optimization by Excel

\section{$\mathrm{Y}=2775.987667 \mathrm{X} 1+33.466 \mathrm{X} 2-$ $5422.18(\mathrm{X} 1)^{\wedge} 2+328.938 \mathrm{X} 1 \mathrm{X} 2$ $19.4801(\mathrm{X} 2)^{\wedge} 2+184.9499$}

The R Square value is 0.992 and significance $F$ is 0.0023 , it means that the analysis is reliable and less probability of error. After the regression function is derived, the equation was optimized by solver tool of Excel and the result is as follow:

Layer Thickness $-0.2 \mathrm{~mm}$

Infill Pattern - $2.55 \sim 3$ - Triangle

Maximum applied force $-649.68 \mathrm{~N}$

It is obvious that the optimization result of both Excel and MATLAB is almost the same. Therefore, the optimization results are reliable and can go to simulation.

\subsection{Validation}

\subsubsection{Actual Simulation}

In order to validate the optimizations results, the actual simulation with optimized values was run. The number of experiments for this simulation is three to make sure the results are reliable. After printing three specimens with layer thickness- $0.2 \mathrm{~mm}$ and infill pattern- triangle and testing with tensile test machine, the results as below were recorded.

Figure (3.2) Optimization of test results According to the results from testing, the mean value of maximum force of three tests is approximately around 609.655 N. Comparing to the optimum value 649.87 , there is a difference about $40 \mathrm{~N}$ between optimization and actual simulation. However, the difference is not much significant and the other factors such as machine condition, ambient temperature, human's error in testing and so on can affect the results. Therefore, the optimization result with respect to simulation result can be concluded that the results are acceptable and valid.

\section{Results and Discussions}

According to the results from DOE and optimization, the influence of the layer thickness is much higher than the influence of the infill pattern. It is significant that the higher layer thickness will give the higher mechanical applied force and strength. Although there are many types of infill pattern, the most common infill patterns were analyzed in this study. Among these three infill patterns, the triangle pattern can give the highest strength. Moreover, triangle pattern can be 
printed with least material consumption according to the Cura software calculation. However, the influence of infill patterns is not significant according to the Taguchi and coefficients from regression function. According to the validation from simulations, the value of optimized parameters and resulted force can be determined as reliable results. The other effects of printing such as machine condition, ambient temperature, skill of temperature, amount of glue applied and so on affected the results more or less.

For the future work, the other types of pattern should be analyzed not only in term of mechanical properties but also in term of cost, material consumption, surface finish and environmental aspects. Moreover, new types of pattern which is more sustainable than current pattern can be created based on the previous studies. Furthermore, the number of experiments should be increased to get more accurate data and results. It would also be helpful to conduct more FEA trials and simulations with different deflections, stresses, and strain. The need to print and test more specimens of each study could help reduce the higher values in standard deviation in the E-Equivalent modulus.

\begin{tabular}{|c|c|c|c|c|}
\hline Simulation & Width & Thickness & Gaguge Length & Max Force(N) \\
\hline Test 1 & 6.15 & 3.42 & 64.66 & $598 . .87$ \\
\hline Test 2 & 6.08 & 3.34 & 63.89 & 607.86 \\
\hline Test 3 & 6.05 & 3.35 & 64.3 & 611.45 \\
\hline & & & Mean Value & $\mathbf{6 0 9 . 6 5 5}$ \\
\cline { 4 - 5 } & & &
\end{tabular}

\section{Conclusion}

Additive manufacturing is expected as the one of most promising maker technologies which can boost the future production technology. However, the technology is still under development stage and need a lot of research to move to commercialization stage. Therefore, the similar studies on effect of parameters to improve the quality of product, scale of product and productivity of machine. This study used DOE, regression function and optimization tools with the help of software such as MATLAB, Minitab, Excel and Weka to do data analysis and optimization. Some conclusions are made as follows:

- Layer thickness have higher influence than infill pattern on mechanical properties

- The higher the layer thickness the higher the mechanical strength

- Triangle pattern gives the highest mechanical strength and lowest material consumption
- $\quad$ Zig Zag pattern gives the lowest mechanical strength

- Unstable machine condition, operation error and other factors can affect the results of printing

\section{ACKNOWLEDGEMENT}

We would first like to thank the Department of Global Production Engineering and Management at Vietnamese-German University.

\section{REFERENCES}

1. Page, C.L., Park, M., Kreuzer, S.M., Ansari, F.L., Eason, D.L., Hamed, E.A., \& Watson, H. (2017). Optimizing 3 D Printed Components : A Methodological Approach to Assessing Print Parameters on Tensile Properties. SPE ANTEC ${ }^{\circledR}$ Anaheim 2017.

2. Tanner D. Harpool (2016). Observing the effects of infill shapes on the tensile characteristics of $3 \mathrm{~d}$ printed plastic parts. Mater Thesis, Department of Industrial Engineering, Wichita State University.

3. Baich, L.J. (2016). Impact of Infill Design on Mechanical Strength and Production Cost in Material Extrusion Based Additive Manufacturing. Master Thesis, Department of Industrial and Systems Engineering, Youngstown State University.

4. Liseli Baich; Guha Manogharan; Hazel Marie (2015). Study of infill print parameters on mechanical strength and production cost-time of $3 \mathrm{~d}$ printed abs parts. International Journal of Rapid Manufacturing, 2015 Vol.5 No.3/4, pp.308 - 319.

5. Lan P. T. Huynh, Huy A. Nguyen, Huy Q. Nguyen, Loc K. H. Phan, Thanh T. Tran (2019). Effect of Process Parameters on Mechanical Strength of Fabricated Parts using the Fused Deposition Modelling Method. Journal of the Korean Society for Precision Engineering, 36(8): 705-712.

6. Bala Murugan Gopalsamy, Biswanath Mondal, Sukamal Ghosh (2019). Taguchi method and ANOVA: An approach for process parameters optimization of hard machining while machining hardened steel. Journal of Scientific \& Industrial Research, Vol 68, pp 686-695, 2009

7. K.H. Choi and T.T. Tran (2010). A new approach for intelligent control system design using the modified genetic algorithm. Int. J. Intelligent Systems Technologies and Applications. 9(3/4). 